(C) 2011 IEEE. Reprinted, with permission, from Brownsell, S., Bradley, D., Cardinaux, F. and Hawley, M. Developing a systems and informatics based approach to lifestyle monitoring within eHealth: part II- analysis \& interpretation. 1st IEEE Conference on Healthcare Informatics, Imaging and Systems Biology, San Jose, California, 26-29 July, 2011 .

This material is posted here with permission of the IEEE. Such permission of the IEEE does not in any way imply IEEE endorsement of any of University of Abertay Dundee's products or services. Internal or personal use of this material is permitted. However, permission to reprint/republish this material for advertising or promotional purposes or for creating new collective works for resale or redistribution must be obtained from the IEEE by writing to pubs-permissionsdieee.org.

By choosing to view this document, you agree to all provisions of the copyright laws protecting it. 


\title{
Developing a Systems and Informatics based approach to Lifestyle Monitoring within eHealth: Part II - Analysis \& Interpretation
}

\author{
Simon Brownsell, David Bradley, Fabien Cardinaux and Mark Hawley \\ ScHARR, University of Sheffield, \\ Regent Court, 30 Regent Street, \\ Sheffield S1 4DA, UK \\ e-mail: s.brownsell@sheffield.ac.uk
}

\begin{abstract}
Lifestyle monitoring as a subset of telecare sets out to use information derived from a range of sensors to put in place a profile of individual behaviour against which changes in behaviour can be compared and referenced to detect variations indicative of a change in health status and need. Based on their research, the authors suggest that in order for lifestyle monitoring to develop, there is a need to more fully understand the way in which such systems operate and how the various aspects such as data collection through to analysis and interpretation come together. The paper therefore presents elements of a system structure for lifestyle monitoring and shows how this structure can incorporate a range of approaches to interpretation and analysis, illustrating this with reference to practical trials involving numeric, analytic and statistical methods as well as a machine learning based approach.
\end{abstract}

Keywords - Computerised monitoring, Health information management, Machine intelligence, Public healthcare

\section{INTRODUCTION}

For lifestyle monitoring to become an accepted and integrated component of care provision implies the capacity to develop a model of individual behaviour based on information derived from sensors within the home and supported by other sources such as observation. This model is then interpreted to identify those behavioural changes associated with a potential change in care need. However, the nature of current systems, and variations between individuals, means that data available for assessing system performance remains limited. Thus, the majority of current lifestyle monitoring systems tend to rely on a number of basic measures which can be readily interpreted either manually or semi-automatically, as for instance whether an individual has become active within a particular time frame.

While this may be a valid approach for many individuals, it is a limited and restricted strategy which is difficult to develop and expand to encompass a wider range of individuals and conditions. Further, the algorithms used tend to be limited in both capacity and scope, and hence in application. However, the results of case studies such as those presented in the paper provide pointers to future lines of algorithm development, along with a recognition of a need for a feedback mechanism linking recorded outcomes to algorithm performance to support their refinement across a full range of users.

This also sugests that the further development of lifestyle monitoring must be structured around means and methods which allow the individual to become much more central to system operation than is the case with the present, necessarily very broad, approach incorporating limited ability to adapt to the individual [1,2]. In particular, systems need not only to be able to respond to general patterns of behaviour, but also be linked to the recording and monitoring of specific behavioural indicators, such as those set out in Table $\mathrm{I}$, in which observation refers to the recording of behaviour by outside individuals such as carers, family and friends, identified in previous work by the authors as being associated with changes in need [3]. This brings with it issues associated with the differences between individuals and the need to build a behaviour profile specific to the individual.

These considerations lead to a definition of an informatics based system structure within which the individual system components can be considered in relation to a series of discrete functional levels as shown in Figure 1. The lower three levels of this structure dealing in detail with data sources, data management and data integration are the subject of a companion paper [4]. This paper then deals in detail with the upper two levels of Data Analysis and Interpretation and System and Information Management respectively.

TABLE I. RELATIONSHIP BETWEEN SELECTED STATUS INDICATORS AND THE ASSOCIATED DATA SOURCES

\begin{tabular}{|c|c|}
\hline Indicator & Data Sources \\
\hline Change in food consumption & $\begin{array}{ll}- & \text { Observation } \\
\text { - } & \text { Activity (Room PIRs) } \\
\text { - } & \text { Appliance sensors } \\
\text { - } & \text { Refrigerator/cupboard use }\end{array}$ \\
\hline Change in food storage & $\begin{array}{ll}- & \text { Observation } \\
- & \text { Refrigerator/cupboard use } \\
\end{array}$ \\
\hline Change in meal preparation & $\begin{array}{ll}- & \text { Activity (Room PIRs) } \\
- & \text { Appliance sensors } \\
\text { - } & \text { Refrigerator/cupboard use } \\
\end{array}$ \\
\hline Change in sleeping patterns & $\begin{array}{ll}- & \text { Activity (Room PIRs) } \\
\text { - } & \text { Bed occupancy } \\
\end{array}$ \\
\hline Change in time spent at home & - $\quad$ Activity (Room PIRs) \\
\hline Change in visitor numbers & $\begin{array}{ll}- & \text { Observation } \\
- & \text { Activity (Room PIRs) } \\
- & \text { Chair/bed occupancy } \\
\end{array}$ \\
\hline Change in washing/bathing & - $\quad$ Activity (Room PIRs) \\
\hline Decline in personal care/ADL & $\begin{array}{ll}- & \text { Observation } \\
- & \text { Activity (Room PIRs) } \\
- & \text { Chair/bed occupancy } \\
\end{array}$ \\
\hline Dirty pots and dishes & $\begin{array}{ll}- & \text { Observation } \\
\text { - } & \text { Activity (Room PIRs) } \\
\end{array}$ \\
\hline General neglect of housework & - $\quad$ Observation \\
\hline
\end{tabular}




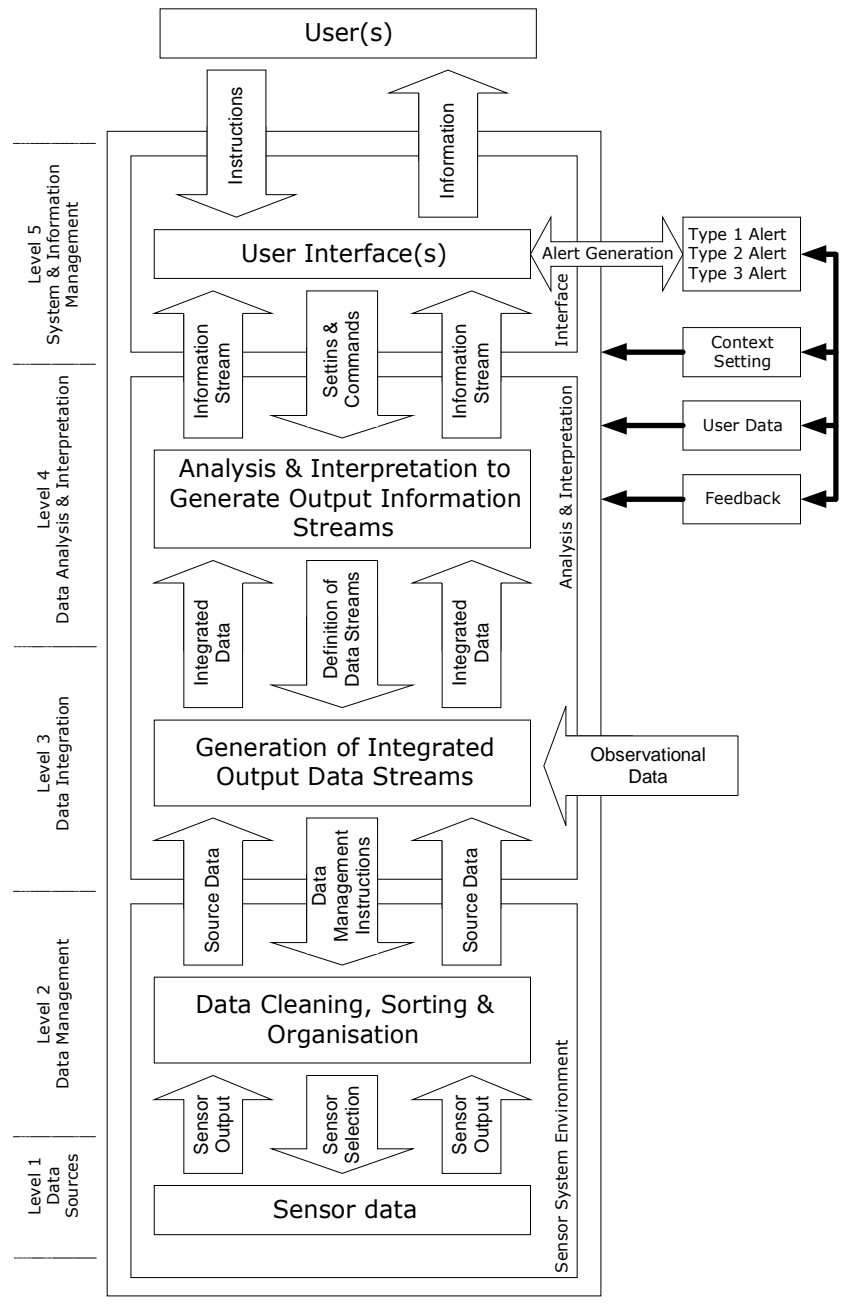

Figure 1. System structure

\section{SYSTEM STRUCTURE}

Figure 1 shows the system structure that it is proposed be associated with a lifestyle monitoring system based on a combination of sensory and observational data. Referring to this figure it can be seen that it is structured around 5 operational levels together with alert generation and management. The operation of the system may therefore be defined in relation to these operational levels. The operation of the lower three layers has been discussed elsewhere [4] and the paper therefore focuses on the operation of the upper two layers of data analysis and interpretation (Level 4) and system and information management (Level 5) in relation to alert generation.

\section{A. Level 4-Data Analysis and Interpretation}

The indicators identified in Table I can each be associated with one or more 'measures', defined here as identifiable behavioural activities and traits capable of being isolated from among general patterns of behaviour. As is clear from Table II for those measures which can specifically be associated with current sensor data, an individual measure could be associated with a number of indicators. It should also
TABLE II. LINKING OF INDICATORS TO RELEVANT MEASURES

\begin{tabular}{|c|c|c|c|c|c|c|c|c|c|c|c|c|}
\hline \multirow[b]{2}{*}{ Indicator } & \multicolumn{12}{|c|}{ Measure } \\
\hline & 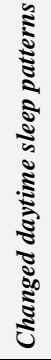 & 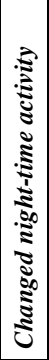 & 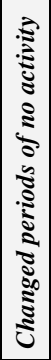 & 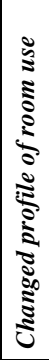 & 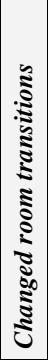 & 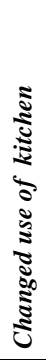 & 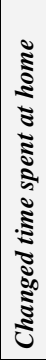 & 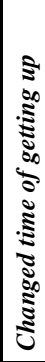 & 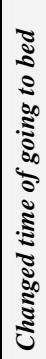 & 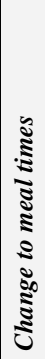 & 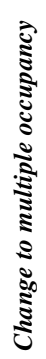 & 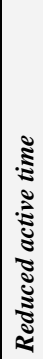 \\
\hline $\begin{array}{l}\text { Change in food } \\
\text { consumption }\end{array}$ & & & & & $?$ & $\checkmark$ & & & & $\checkmark$ & & \\
\hline $\begin{array}{l}\text { Change in food } \\
\text { storage }\end{array}$ & & & & & & $?$ & & & & & & \\
\hline $\begin{array}{l}\text { Change in meal } \\
\text { preparation }\end{array}$ & & & & & & $\checkmark$ & & & & ? & & \\
\hline $\begin{array}{l}\text { Change in } \\
\text { sleeping patterns }\end{array}$ & $\checkmark$ & $\checkmark$ & & & $?$ & & & $\checkmark$ & $\checkmark$ & & & \\
\hline $\begin{array}{l}\text { Change in time } \\
\text { spent at home }\end{array}$ & & & & & & & $\checkmark$ & & & & & \\
\hline $\begin{array}{l}\text { Change in visitor } \\
\text { numbers }\end{array}$ & & & & & $?$ & & & & & & $\checkmark$ & \\
\hline $\begin{array}{l}\text { Change in } \\
\text { washing/bathing }\end{array}$ & & & & & $?$ & & & & & & & \\
\hline $\begin{array}{l}\text { Decline in } \\
\text { personal } \\
\text { care/ADL }\end{array}$ & & & $\checkmark$ & $\checkmark$ & $?$ & ? & $\checkmark$ & & ? & ? & & $\checkmark$ \\
\hline
\end{tabular}

TABLE III. EXPRESSION OF MEASURES

\begin{tabular}{|l|l|}
\hline Measure & Basis for algorithm \\
\hline $\begin{array}{l}\text { Changed daytime sleep } \\
\text { patterns }\end{array}$ & $\begin{array}{l}\text { The time during daytime spent in or on the } \\
\text { bed. }\end{array}$ \\
\hline $\begin{array}{l}\text { Change in night-time } \\
\text { activity }\end{array}$ & $\begin{array}{l}\text { The number of times the bed is left at night } \\
\text { and the total amount of time spent out of bed. }\end{array}$ \\
\hline $\begin{array}{l}\text { Change in periods of no } \\
\text { activity }\end{array}$ & $\begin{array}{l}\text { The time while in the house during daytime } \\
\text { when no activity is recorded. }\end{array}$ \\
\hline $\begin{array}{l}\text { Change in profile of room } \\
\text { use }\end{array}$ & $\begin{array}{l}\text { The number of times that a room is used } \\
\text { together with the total time spent in each } \\
\text { room. }\end{array}$ \\
\hline Change in room transitions & $\begin{array}{l}\text { The number and frequency of transitions } \\
\text { between individual rooms. }\end{array}$ \\
\hline Change in use of kitchen & $\begin{array}{l}\text { The time spent in the kitchen and the } \\
\text { distribution of use throughout the day. }\end{array}$ \\
\hline $\begin{array}{l}\text { Change in time spent at } \\
\text { home }\end{array}$ & $\begin{array}{l}\text { The time spent indoors as a proportion of time } \\
\text { between getting up and going to bed. }\end{array}$ \\
\hline $\begin{array}{l}\text { Change in time of getting } \\
\text { up }\end{array}$ & The time the bedroom is left in the morning. \\
\hline $\begin{array}{l}\text { Change in time of going to } \\
\text { bed }\end{array}$ & $\begin{array}{l}\text { The time when the person goes to bed in the } \\
\text { evening. }\end{array}$ \\
\hline Change to meal times & $\begin{array}{l}\text { The times of use of the kitchen throughout the } \\
\text { day }\end{array}$ \\
\hline $\begin{array}{l}\text { Change to multiple } \\
\text { occupancy }\end{array}$ & $\begin{array}{l}\text { Simultaneous activation of the motion } \\
\text { sensors in different rooms. }\end{array}$ \\
\hline Reduced active time & $\begin{array}{l}\text { The recorded active time as a function of the } \\
\text { total daytime time. }\end{array}$ \\
\hline &
\end{tabular}


be noted that some of the measures are implicitly embedded in others. Thus, the measure 'Change in profile of use of kitchen' is a component of the measure 'Change in profile of room use'. This then leads to the relationships of Table III.

Consider the measure Change in profile of use of kitchen. There then exist a number of potential relationships which could be used to quantify this measure such as those set out below.

1) The time spent in the kitchen $\left(\mathrm{T}_{\text {Kitchen }}\right)$ as a proportion of the defined daytime period $\mathrm{T}_{\text {In.Daytime }}$ such that:

$$
T_{\text {In.Daytime }}=\left(T_{\text {Daytime }}-T_{\text {Out.Daytime }}\right)
$$

where:

$T_{\text {Daytime }}$ is the overall daytime period defined as $\left(T_{\text {Daytime.End }}\right.$ $\left.-T_{\text {Daytime.Start }}\right)$

and

$T_{\text {Out.Daytime }}$ is then the time spent out of the house during the period $T_{\text {Daytime. }}$

When:

$$
\text { Kitchen.Day }=\frac{\sum T_{\text {Daytime }}}{T_{\text {Daytime }}-T_{\text {Out.Daytime }}}=\frac{\sum T_{\text {Daytime }}}{T_{\text {In.Daytime }}}
$$

in which $\sum_{T_{\text {Daytime }}} T_{\text {Kitchen.Occupied }}$ is the total time for which

the Kitchen.Occupied.Flag is set during daytime, indicating that activity has been detected in the kitchen. Thus:

$$
\begin{aligned}
& \text { SET } T_{\text {Kitchen.Occupied }}=0 \\
& \text { FOR Time }=T_{\text {Daytime.Start }} \text { TO } T_{\text {Daytime.End }} \\
& \quad \text { IF Kitchen.Occupied.Flag SET THEN } \\
& \quad T_{\text {Kitchen.Occupied }}=T_{\text {Kitchen.Occupied }}+T_{\text {Increment }} \\
& \text { WHEN 'Daytime.End' THEN } \\
& \text { Kitchen.Day }=\left(T_{\text {Kitchen.Occupied }}\right) /\left(T_{\text {Daytime }}-T_{\text {Out.Daytime }}\right)
\end{aligned}
$$

in which $T_{\text {Increment }}$ is the duration of the time step used to record activity

2) The number of daily transitions to and from the kitchen averaged over a period of ' $D$ ' days such that:

$$
\text { Average.Kitchen.Transitions }=\frac{\sum_{i=1}^{D} K_{\mathrm{Kitchen} \cdot \operatorname{Transition}(i)}}{D}
$$

In which $K_{\text {Kitchen.Transition }(i)}$ is the number of transitions on day (i) and so on for the ' $D$ ' days for which the average is taken. Thus:

$$
\begin{aligned}
& K_{\text {Kitchen.Transition }}=0 \\
& \text { FOR Current.Day TO Current.Day }-(D-1) \text { SET } \\
& \qquad \begin{array}{r}
\text { Kitchen.Transition } \\
=K_{\text {Kitchen.Transition }}+K_{\text {Kitchen.Transition(Day) }} \\
\text { THEN Average.Kitchen.Transitions } \\
=\left(I_{\text {Kitchen.Transition }}\right) / D
\end{array}
\end{aligned}
$$

Similar relationships can be defined for others of the measures of Table III. However, there is at present insufficient data with the appropriate levels of discrimination
TABLE IV. SUMMARY OF ERRORS ASSOCIATED WITH OPERATION OF PRIMARY TELECARE SENSORS DURING LABORATORY TESTING

\begin{tabular}{|l|r|r|}
\hline & Missing & Spurious \\
\hline Electrical (power) sensors & $9 / 130(7 \%)$ & 16 \\
\hline $\begin{array}{l}\text { Door/Drawer open/close } \\
\text { (individually) }\end{array}$ & $10 / 160(6 \%)$ & 4 \\
\hline Bed/Chair occupancy & $25 / 97(26 \%)$ & 6 \\
\hline PIR & $9 / 440(2 \%)$ & 61 \\
\hline $\begin{array}{l}\text { Door/Drawer open/close } \\
\text { (simultaneous activations) }\end{array}$ & $40 / 50(80 \%)$ & 0 \\
\hline Total & $133 / 877(15 \%)$ & 87 \\
\hline
\end{tabular}

and degree of proven robustness, as expressed in terms of its reliability and freedom from error as established by tests carried out by the authors, the overall results of which are given by Table IV [4], available to provide other than a basic indication of the forms of data evaluation to be used. It is therefore proposed that future trials should consider running a in parallel, after which evaluative methods, including those based on machine learning, would be used to choose the appropriate format for an individual.

\section{B. Level 5 - System and Information Management}

It is at this level that the system users can interact with the system to define the way in which it operates as well as the interactions with the wider world. Thus, on setting up the system, the type and position of the network sensors would be defined along with the indicators and measures to be used. At the same time, the threshold values and type associated with the means to be used for the analysis and interpretation of the information streams would be established.

This in turn would then link into the response protocols, which it is at this stage envisaged to be structured around the following three levels of alert:

Type 1 - A simple response is requested from the user to act as a confirmation of their status.

Type 2 - A warning is sent to the appropriate responder that a possible change in status requiring a response has been detected and initiating a follow-up.

Type 3 - An emergency requiring an immediate response.

This level also contains the feedback mechanisms associated with the updating of the system performance in line with user need. Ideally, this should encompass not only direct feedback derived from the status of the user, but also incorporate feedback from other users with similar backgrounds and conditions. This in turn implies an need for an integrated system across numbers of users in which knowledge gained from an individual user is combined with knowledge about all other users to maximise the ability of the system to detect specific behavioural changes.

It is recognised that this is a complex process and is one which the authors and others are only beginning to address as it requires access to data across many users and implies the application and implementation of techniques such as knowledge discovery and data mining to establish the 
behavioural database against which individual behavioural change can be assessed.

\section{ANALYSIS AND INTERPRETATION}

A key element of the data analysis and interpretation process is the ability to link the data to an appropriate form of visualisation and this is therefore a feature of the methods considered here. Two approaches are proposed, one based on the use of algorithmic and analytic methods such as trend lines and the other using machine learning strategies to identify abnormal conditions.

In either case, the aim is to isolate those behavioural patterns which can be linked initially to the defined measures, and hence ultimately to the indicators of a change in need, and which will form the basis of the lifestyle monitoring approach. Thus, the aim is to establish behavioural elements such as:

- The occupancy of monitored space and the time for which such space is occupied.

- The level of activity within a monitored space for the period that a space is occupied, which will in turn vary with the nature of the activity.

- The level of inactivity associated with the occupancy of a space. This may be contrasted with the measure of the level of activity and sudden transition between a period of activity to one of inactivity could be a significant feature.

- Transitions between spaces expressed in terms of (a) the number of transitions; (b) the frequency of transitions and (c) the pattern of transitions.

And perhaps ultimately:

- Multiple occupancy of space, based on more than one space being occupied at a point in time

- Daily and weekly patterns of behaviour including the identification of specific activities such as breakfast.

- General and specific activity profiles such as general daily, weekly or monthly levels of activity as recorded by PIRs.

- User profiling for features such as the use of appliances or the use of space.

Of particular concern is the issue of establishing the 'normal' or 'baseline' behaviour for each individual which in turn may be dependent upon circumstances, as for instance following discharge from hospital where improvement over time is a key criteria or more general long-term monitoring looking for behavioural changes, and potential deterioration. This raises questions such as:

- The period of time over which a system needs to be in place to establish a stable base.

- The use of an 'assumed' initial baseline based on an anticipated behaviour derived from an evaluation of the user.

In this context, the use of machine learning strategies combined with pre-established baseline criteria could provide a means of adapting systems to the individual by autonomously revising and adapting key parameters over time. However, the evidence for the effectiveness of such strategies is minimal to date and based on a small number of

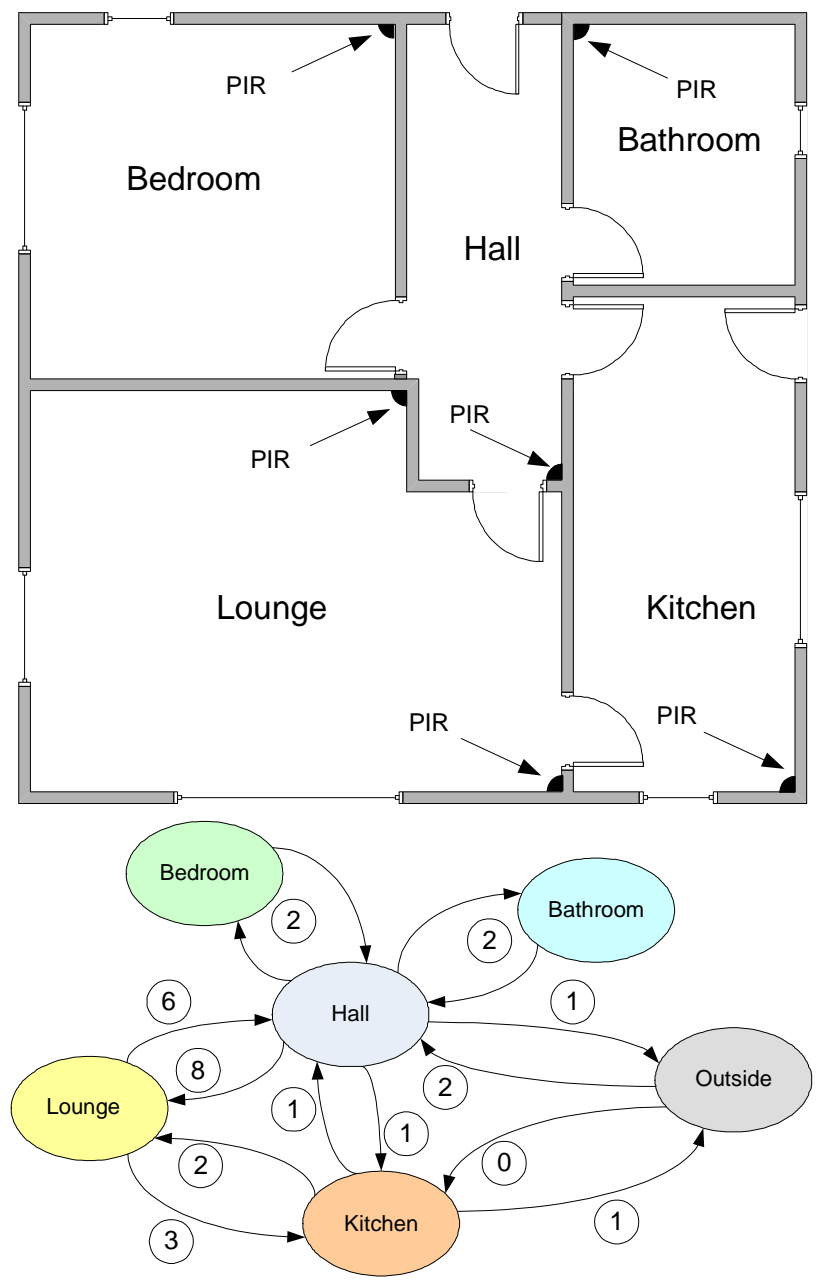

Figure 2. Transition monitoring: (a) Room layout, (b) Transition diagram with numbers of transitions,

experiments such as that considered in the case studies reported in the paper.

\section{A. Algorithmic \& analytic methods}

(1) Transitions \& room occupancy: Consider the room layout of Fig. 2a,. The associated transition diagram, including the recorded number of transitions, will then be of the form shown in Fig. 2b. Once the transitions are known, it is possible to infer activities based on these. Thus, a failure to record the occupancy of the Hall following a transition from Lounge to Kitchen, which must pass through the Hall, can be replaced by an inferred occupancy plus an indication of a potential failure of the Hall sensor. Similarly, a transition from Lounge to Kitchen (via the Hall) with continued activity in both spaces would be indicative of a visitor (in normal single occupancy dwellings). This could then be further confirmed by reference to the occupancy of the hall and the opening and closing of the door to the outside.

Once transitions are recorded, the level of activity (or inactivity) associated with room occupancy can be established and collated with other of data, as for instance the use of the television or chair occupancy to generate a profile of the room use. 
(2) Activity measures: These can be considered in relation both to specific and specified activities such as making breakfast for which kitchen based actions in a defined time interval would be considered indicative of the activity and to more general expressions of activity integrating information such as room transitions and the use of the television and other appliances to create a daily activity profile. In practice, it is likely that some combination of the general and the specific would be incorporated into the analysis.

(3) Trendlines: These are perhaps the simplest means of interpreting time series data containing a variance around a mean value by removing short term variations in the data to reveal the underlying trends. For conditions associated with a situation where change may occur progressively over a period of time, a range of information options can be associated with any of the identified indicators.

In setting the response threshold values, consideration as to whether absolute values or percentage values are used to express the thresholds can be important. For instance, if the established range of parameter variation is large, then the use of a percentage value to express the degree of variation required to trigger a response may result in the detection range being too small and the use of an absolute value for change may then be more appropriate. Similarly, if the range of variation is small, the use of an absolute value to express the limits of parameter variation may result in the thresholds being set too high and a percentage change may thus be more appropriate. However, each situation and each individual must be considered on its own merits and in relation to the established behaviour profiles of the individual.

(4) Scatter Diagrams \& Box Plots: Where a specific situation, as for instance the number of times a particular activity occurs in the course of a week, a scatter diagram or box plot could be considered.

\section{B. Machine learning methods}

Machine learning aims to support the autonomous development and evolution of methods and algorithms based on empirical data. A major element of machine learning is thus the creation of an ability to recognise complex patterns within data sets, and hence to make intelligent decisions based on that data.

The process of novelty detection $[5,6]$ within machine learning then refers and relates to the identification of new or unknown data or signals that the machine learning system is not aware of during training. Novelty detection is therefore a one-class classification process. The known data form one class, and a novelty detection method deployed tries to identify outliers that differ from the distribution of ordinary data, which formed the single data class. Compared to multi-class classification, one-class classification is useful if outliers are sparse compared to ordinary data.
Machine learning approaches are in general based on making an estimate of a particular characteristic or characteristics of the distribution of the normal class from training data, and then using this to estimate how 'novel' a test point is. Due to the absence of a priori information on the distribution of novel events, any novelty detection system will of necessity identify some normal data as novel (false alarms). An important characteristic of the system is thus its ability to accurately predict the rate with which such false alarms will be generated. Depending on the application, it is important to balance the cost of letting some novelties pass undetected, and the cost of raising too many false alarms.

When considering the status of potentially vulnerable individuals, it is essential to have a system which could become operational and effective after the shortest possible training period. This in turn leads to a consideration of the problems of estimating abnormal behaviour within very short data streams. In this instance therefore the novelty detection problem is recast in the framework of information theory when the approach focuses on computing the distribution of the information content carried by a new data point.

\section{CASe Study I - ApPlication of Algorithmic AND ANALYTICAL METHODS}

The following refers to a the monitoring of a real individual where changes were observed prior to admission to hospital. The sensor fit used in the study comprised:

- PIR motion sensors in each room.

- A sensor to detect the opening and closing of the refrigerator.

- Sensors to detect the opening and closing of cupboards

- A chair occupancy sensor in the main room

- A bed occupancy sensor The data plotted was then:

1. The trendline of Fig. 3 which relates to the general level of activity, i.e. $T_{\text {Active.Day }}$, the total active time recorded within a given 24 hour period.

2. Trendlines of activity for specific rooms. Figure 4 shows that for the kitchen and Fig. 5 that for the bedroom as these are of the most significance in this instance.

3. A scatter diagram, shown as Fig. 6, for daily levels of activity for weekdays (Monday to Friday) only.

In each case the graphs were plotted using the cleaned (de-bounced and missing events recorded) data using a standard graphing package. They were then reviewed manually to establish if any trends were discernable in the data prior to hospital admission and if these could have been detected using any of the proposed algorithms operating autonomously [7]. 
TABLE V. CASE STUDY I - USER LOG

\begin{tabular}{|c|c|l|}
\hline Week & Day & \multicolumn{1}{|c|}{ Notes } \\
\hline 1 & 1 & Start of trial \\
\hline 2 & 9 & Woken by phantom limb pains \\
\hline & 12 & Eating more than usual \\
\hline 4 & 25 & Cut finger on glass, bled profusely \\
\hline 5 & 29 & Felt unwell - high blood pressure - short of breath \\
\hline & 31 & No improvement - short of breath - very tired \\
\hline & 32 & Breathing still bad \\
\hline & 33 & $\begin{array}{l}\text { No improvement - breathless - extremely tired -extremely } \\
\text { weak }\end{array}$ \\
\hline & 34 & No change - still short of breath- extremely tired and weak \\
\hline & 35 & Still as above \\
\hline 6 & 36 & $\begin{array}{l}\text { Hospital admission in view of the deterioration condition. } \\
\text { In hospital for one week before discharged home. }\end{array}$ \\
\hline
\end{tabular}

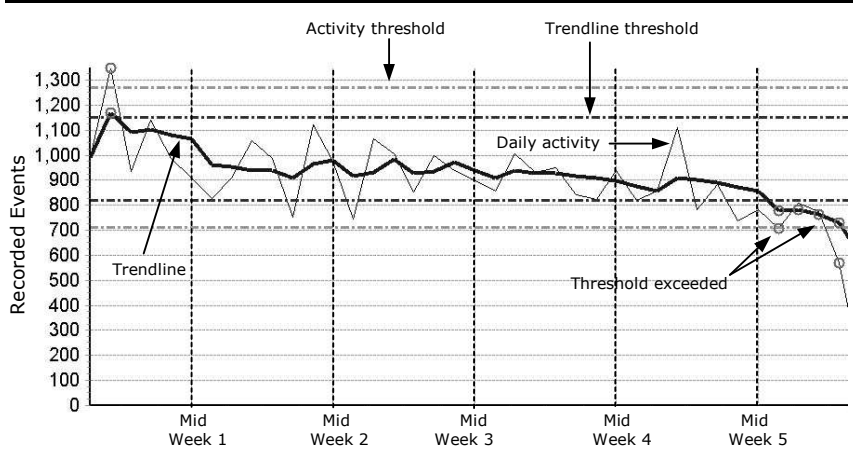

Figure 3. General level of activity

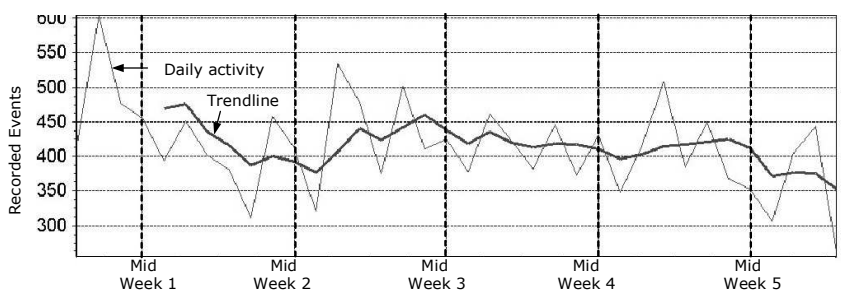

Figure 4. Kitchen activity

To supplement and reinforce the data from the sensors, the individual being monitored was also asked to keep a log, a summary of which is given as Table $\mathrm{V}$ showing all information recorded by the user up to the point at which they were admitted to hospital. No other form of observational data, as for instance from a warden or carer, was included in the analysis and review process.

Referring to the figures, the kitchen activity shows a dip in week 2 even though the individual noted in that week on Day 12 that they were 'eating more'. At the same time there is an increase in time spent in the bedroom whilst the overall level of activity remains steady, something which is confirmed by the scatter diagram which shows a reasonably stable level of activity between days in the first three weeks of the period.

However, from week 3 on there is a steady decline in the

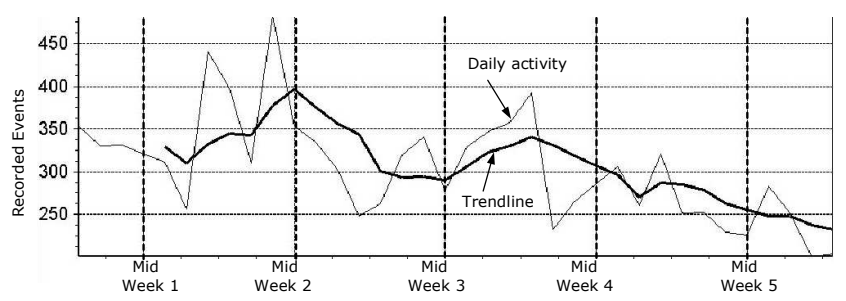

Figure 5. Bedroom activity

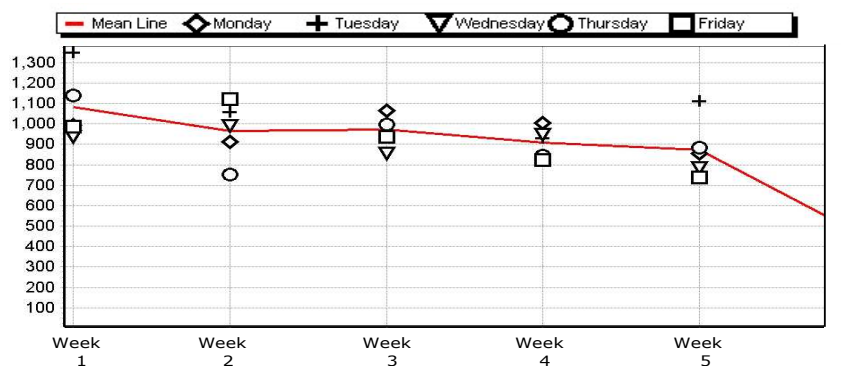

Figure 6. Scatter diagram for general activity level on weekdays

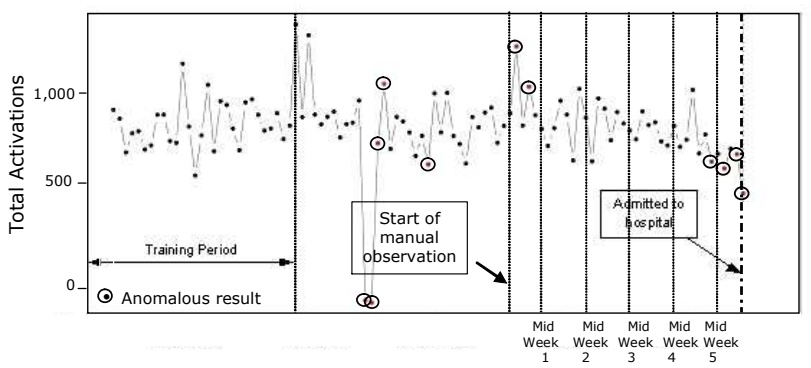

Figure 7. Machine analysis data and anomaly detection using activations of the refrigerator as basis.

trend lines for general activity as well as for both kitchen and bedroom activity. This latter is again particularly interesting as the individual notes throughout week 5 that they are feeling tired, which suggests that they are resting at a location other than the bedroom, i.e. in a chair, but not necessarily that to which the chair occupancy sensor was fitted. Finally, the extreme downward trend on the scatter diagram is due to the limited data set for the final week.

\section{Case Study II - Application of Machine LEARNING METHODS}

Following on from the case study above, it was decided that the same data set, containing a known and identified behavioural status change, would be used to examine machine learning strategies. However, following a review of the data volumes, it was decided that rather than consider the overall level of activity the activation of the refrigerator would be used to see if this provided a more direct and observable link to the recorded outcomes.

Following this decision, the analysis began by processing the relevant sensor data to construct a time series containing the daily total of refrigerator activations. Since an "open" action should in general be followed by a "close" one, the 
number of total activations was divided by $2^{1}$. Also, as the system is dealing with counts that are positive numbers, it is possible to encounter situations where the distribution of count is strongly skewed. In order to cope with this condition, a logarithm transformation of the form $\log (\mathrm{x}+1)$ was applied in which ' 1 ' was added to deal with the situation of there being no counts in a day $(x=0)$.

The algorithm to be used for novelty detection was trained using the first 80 days worth of data. As it was not known how many past observations would be needed to model the time series (the model order), this was left to the algorithm to determine on the basis of the Akaike information criterion (AIC) [8]. For this individual this resulted in a model order of 2. A $1 \%$ rejection rate was then selected, this means that on the basis of the test data, it would be expected to see $1 \%$ of false positives. If numbers of novelties in excess of this are observed, doubts can be raised as to the normality of the test data.

The results are shown in Fig. 7 which shows both the training period and the test period. As the analysis of the data was being carried out autonomously, it was able to examine a longer period than was practical manually which covered only the period of the diary. This also had the advantage that it allowed a further check on the performance of the machine learning algorithms by operating them over a period in which there were known outcomes. Referring to Fig. 7, this shows that there was a series of unexpected activations of the fridge towards the end of the study and that the overall result is consistent with that using algorithmic and analytic methods.

\section{DISCUSSION}

The case studies presented would seem to suggest that if the appropriate algorithms had been in place then, for the individual concerned, the change in their condition would have been detected, and hence responded to, earlier than was in fact the case. However, a review of other cases showed no similar, or marked, evidence of significant changes leading to a change in status. While this may be associated with the nature of the individual cases, and the limited number of cases, it may also be a function of the methods being used.

Indeed, the levels of variability in behaviour between individuals, and the need for systems to adapt to such variability, is recognised and the concept of a 'fuzzy day' within which an individual's activities can be placed has therefore been mooted $[9,10]$. While the concept of fuzziness at the level of the day is valid in this context, in describing a person's behaviour, there are in practice multiple fuzzy layers involved. In addition to a fuzzy day, the authors suggest that there needs to be an associated 'fuzzy' or 'probabilistic' week within which various activities, both internal and external to the home environment, are structured and defined. Thus, the fuzzy probability of going shopping on a particular day will be used to modify the fuzzy structures for the day in question. Should shopping not occur that day, then the probabilities of it taking place on another day will be adjusted accordingly. It is also considered to be highly likely that there then needs to

\footnotetext{
${ }^{1}$ As cleaned data was used with all effects such as contact bounce removed, this was a valid assumption.
}

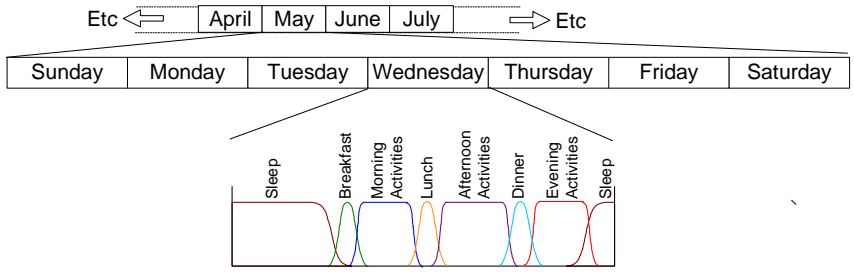

Figure 8. Fuzzy days plus higher fuzzy levels

be further fuzzy layers such as the 'fuzzy month' and 'fuzzy year' as suggested by Fig. 8 if behaviour is to be properly defined.

Given the relative lack of evidence relating to the outcomes of lifestyle monitoring systems [1], the means by which such structures may be defined remains unclear. The gathering of robust evidence is of necessity something which involves a significant time scale and will, as has already been suggested, almost certainly involve the use of techniques such as knowledge discovery and data mining at the level both of the individuals and groups of individuals over large numbers of subjects.

When considering the relative performance of conventional and machine learning approaches it would seem that both are likely to be capable of responding to relatively long term variations in, but that machine learning may be more effective in responding to unanticipated circumstances.

However, the difficulties of proceeding with the sparse data generated by a limited number of tests sites where the behaviour of the individuals can neither be controlled or predicted creates difficulties in developing system understanding.

\section{CONCLUSIONS}

While the case studies suggest that there is a potential for methods such as those described to provide information about individual behaviour which could be used to support early care interventions, they also indicate the problems associated with taking forward this concept on any significant scale. In particular, the small data set encompassing only 24 individuals means that there is limited opportunity to evaluate the methods. Indeed, as was indicated earlier, other users of the system required external interventions with there being no detectable variation in their data to indicate the need for such interventions.

This lack of a real understanding of the analysis procedures as applied to real data has led to the development of a simple behavioural simulator aimed at providing the ability to reproduce specific, simple, conditions such as a change in the daytime sleep patterns or use of the kitchen or bathroom. However, while the simulator serves to point up issues with both the sensors and the analysis process, the real need is for more significant data involving multiple algorithms being run in parallel across a large number of users for an extended period of time. This suggests that a way forward may be for groups working in the field, both academic and commercial, to come to an agreement over data sharing to allow the for its retrospective analysis using a 
variety of approaches. It is acknowledged that this raises significant issues of access and confidentiality, but would have significant benefits in driving matters forward in the short to medium term.

Another factor is the quality and robustness of the data. As tests by the users have shown [4], there can be significant false readings resulting from a variety of factors ranging from the positioning of the individual sensors to contact bounce. Whilst a degree of data cleaning and management can be used to remove some of these erroneous readings, there are still issues regarding data quality that need to be addressed and resolved before full confidence in outcomes can be achieved.

By considering all installations as essentially experimental in nature, and be putting in place appropriate reporting and feedback mechanisms, the opportunity is there to increase understanding of individual behaviour and to provide enhanced care. In the absence of such integration, it is argued that progress will continue to be patchy and relatively slow.

\section{ACKNOWLEDGEMENTS}

The paper is based on independent research commissioned by the National Institute for Health Research in the UK. The views expressed in this publication are those of the author(s) and not necessarily those of the UK National Health Service, the National Institute for Health Research, or the UK Department of Health.

\section{REFERENCES}

[1] S Brownsell, DA Bradley, S Blackburn, F Cardinaux \& MS Hawley, "A systematic review of lifestyle monitoring technologies", J. Telemedicine and Telecare, 2011, 17:185 - 189

[2] S Brownsell, DA Bradley, S Blackburn, F Cardinaux, \& MS Hawley, "A review of behavioural monitoring methods and recommendations for future development", Intl. Society of Gerontechnology, 2010, 9(2): page 20

[3] S Brownsell, H Aldred \& MS Hawley, "The role of telecare in supporting the needs of elderly people", J. Telemedicine \& Telecare, 13(6), 2007: 293 - 297

[4] S Brownsell, DA Bradley, S Blackburn, F Cardinaux, \& MS Hawley, "Developing a Systems and Informatics based approach to Lifestyle Monitoring within eHealth: Part I - Technology and Data Management", IEEE Conf. on Healthcare Informatics, Imaging, and Systems Biology (HISB 2011), 2011, Paper 26

[5] SJ Roberts, "Novelty detection using extreme value statistics", IEEE Proc. On Vision, Image \& Signal Processing, 1999, 146(3):124 - 129

[6] M Filippone \& M Sanguinetti, "Information theoretic novelty detection", Pattern Recognition, 2010, 43(3):805 - 814

[7] F Cardinaux, S Brownsell, DA Bradley \& MS Hawley, "Case study evaluation of an advanced lifestyle monitoring system", Intl. Conf. on Aging, Disability \& Independence, ICADI 2010, 2010, Abstracts only, page 55

[8] H Akaike, "A new look at the statistical model identification", IEEE Trans. on Automatic Control, 1974, 19 (6): 716-723

[9] T Martin, B Majeed, Beum-Seuk Lee and N Clarke, "Fuzzy Ambient Intelligence for Next Generation Telecare", IEEE Int. Conf. on Fuzzy Systems, 2006, pp 894 - 901.

[10] L. Litz and M Gross, "Covering Assisted Living Key Areas based on Home Automation Sensors", IEEE Int. Conf. on Networking, Sensing \& Control, 2007, pp 639 - 643. 